\title{
ROY'S INGLISH IN THE GOD OF SMALL THINGS: A LANGUAGE FOR SUBVERSION, RECONCILIATION AND REASSERTION ${ }^{1}$
}

\author{
Agustín Reyes Torres, Universitat de València \\ Email: agustin.reyes@uv.es
}

\begin{abstract}
In The God of Small Things, Arundhati Roy separates English from Englishspeakers. She reappropriates the language not only to portray complex characters and narrative themes, but also to create a postcolonial discourse that criticizes, questions and subverts the old dominance of the imperial colonizer. Mainly addressed to a western audience, the use of Inglish in this novel is a crucial factor to reveal the development of a hybrid conscience, reassert the Indian identity and make the reader feel displaced from their native tongue

Keywords: English language, postcolonial, hybridity, Indian identity, discourse

Título en español: El Inglish de Roy en The God of Small Things: Una lengua para la subversión, la reconciliación y la reafirmación.

Resumen: En The God of Small Things, Arundhati Roy distancia al hablante-nativo de inglés de su propia lengua. El inglés que utiliza no solo presenta personajes y temas complejos, sino que crea un discurso poscolonial que critica, cuestiona y socava el antiguo dominio del colonizador. Dirigida principalmente a un lector occidental, el Inglish de Roy en esta novela es determinante para representar el desarrollo de una conciencia hibrida, reafirmar la identidad india y lograr que los hablantes nativos de inglés se sientan extraños con su propia lengua.

Palabras clave: Inglés, poscolonial, mestizaje, identidad india, discurso
\end{abstract}

\begin{abstract}
"We cannot write like the English. We should not. We cannot write only as Indians. We have grown to look at the large world as part of us."
\end{abstract}

Raja Rao

The God of Small Things (1997) is a novel written completely in English, but from the perspective of characters who do not natively speak the language. Arundhati Roy employs several techniques, including unconventionally placed capitals, extensive use of sentence fragments, and playful reflections on the sound or construction of words, in order to offer the reader the perspective of characters that are not wholly comfortable in the realm of English.

Date of reception: 11 June 2011

Date of acceptance: 29 November 2011

Odisea, n ${ }^{\circ} 12$, ISSN 1578-3820, 2011, 195-204 
This serves as the prime postcolonial facet of the novel; the reader is shown what it is like to have English imposed. The author's unique style is often interpreted as undermining the dominance of accepted norms of English grammar with its linguistic acrobatics (Volkmann 2008: 463), thus contributing to the novel's harsh exposure of the persevering influence of colonialism.

Roy's first novel can be set in the wider tradition of what is often called Indo-Anglian writing, one of several terms for Indian writing written in English. This tradition spread first after its establishment as the language of the Indian Civil Service and thus of the administration and maintenance of Empire. The rise of the Indian novel in English, however, is linked particularly to the generation of authors writing in the 1930s which included Raja Rao and R.K Narayan. Decades later, it would be followed by writers as various as V.S. Naipaul, Amitav Ghosh, Anita Desai, Salman Rushdie and Vikram Chandra among others. Today Indo-Anglian fiction is largely a transnational, diasporic phenomenon that reveals that India itself is a hybrid creation, a conglomeration of what was brought in from outside, absorbed and reworked.

Taken to the level of language, hybridity must be understood, according to Mikhail Bakhtin, as "a mixture of two social languages within the limits of a single utterance, an encounter, within the arena of an utterance, between two different linguistic consciousness, separated from one another by an epoch, by social differentiation or by some other factor" (cited in Young 1995: 20). The use of language is in this way a crucial factor not only in determining identity and how speakers see themselves but also in creating thoughts and a concept of the world. Roy's portrayal of Rahel and Estha's use of Inglish throughout the novel reveals on the one hand the development of a hybrid conscience, and on the other, the author's reappropriation of the imperial English to release it from the ideology and the political loadness of the old colonial discourse. As Homi Bhabha puts it, hybridity here is symbolized by "the moment in which the discourse of colonial authority loses its univocal grip on meaning and finds itself open to the trace of language of the other, enabling the critic to trace complex movements of disarming alterity of the colonial text" (1990: 22).

As much as language creates contexts and shapes perception, it can also be modified and created by its contexts and users. The first reality was well known by the European colonizing powers as they brought to indigenous world peoples brand new languages with histories of concepts, canons of literature, and biblical truths that were to replace so-thought inferior languages and religions. Indeed the colonization was so effective that many of the colonized began to believe themselves to be inferior, along with their language and traditions, and soon learned English, Christianity and all the rest. Yet post-colonial literature has made significant efforts to reclaim the oral and literary traditions of the colonized through a sort of refashioning of English. The God of Small Things is a prime example of the exploration and modification of the English language as created by Anglos. Roy's ironic position as an Indian writer with extraordinary command of the nuances in English places her in a unique position within the words of the text. She commands the language of the novel and its characters, ultimately weaving a text that reconsiders itself and the complete experience of language.

Through many means of manipulating language, Roy is able to enlighten her text, her characters, and her readers. Just as the story is nonlinear, the language in the novel follows 
suit, creating a sense of near dysphasia in the beginning by convoluting past and present, and major plotline with minor plotline. Readers stumble to get their bearings on who is speaking, where the story is taking place and when, and why details are used like a sign that displays the world "POLICE" (Roy 1998: 10) as an acronym. This confusion and discomfort felt on the part of readers assists Roy's purpose to place us, if only temporarily, in the shoes of the colonized. We have to relearn the way a story might be told, and we must accept what seem like interruptions to the flow of a narrative with words in their proper places. As Mary Snell-Hornby indicates, this “"new English' with its own individual language 'norms', along with the many 'exotic' cultural-bound items, which in their entirety often carry the message of the text, present a genuine challenge for the [reader's] capacity of understanding, and for his or her creative powers (2003: 187). In the case of native speakers of English, they are displaced from their native tongue and custom to enter a new textual world with different rules yet to be learned.

This effect is continued throughout the novel vis-à-vis Rahel and Estha's childhood experience with English. Baby Kochamma insists upon their use of the language, a foreign tongue to them, and they wreck, mould, misuse and discover it to great effect. Roy describes the dizzying and difficult meeting between Estha, Rahel, and Sophie Mol utilizing the unusual lexicon through which the twins seem to view their world. Hiding behind dusty curtains to avoid the awkward "How do you do" for Sophie Mol: "Ambassador Rahel wouldn't come out of the curtain because she couldn't. She couldn't because she couldn't. Because everything was wrong. And soon there would be a LayTer for both her and Estha. (Roy 1998: 139-40). For Estha, "Baby Kochamma's neckmole licked its chops and... changed colors like a chameleon. Der-green, der-blueblack, der-mustardyellow" (Roy 1998: 141). The twins attempt to avoid the situation for all their discomforts and uncontrollable fixations. Not only are they coping with Ammu loving Rahel a little less and the OrangeDrink LemmonDrink man's intrusions, but they also are forced to act as if they too were British like Sophie Mol. They must act and speak 'properly,' outside of their normal customs and native language. Yet Rahel's thoughts are disoriented and regressive, attempts at avoiding the meeting with Sophie Mol, and the subsequent conversation, at all costs.

Roy's depiction of the twins' reaction suggests the discomfort of acting outside oneself that is undoubtedly felt by the colonized, needing to act and speak according to the dominating culture. On this note, as Richard Lane points out, the author's focalization on Rahel and Estha also gives the reader "access to the children's minds, making apparent the often incomprehensible and threatening adult world" (2006: 99). In this case, the twins react by fixating on the familiar, through an awkward internal narrative, ashamed of the "LayTer" they knew was coming and repulsed by the chop-licking neckmole that was the now. Baby Kochamma and Chacko, Anglophilic and English-educated, compound the situation by acting the role of the colonized subjects. They embody what Lois Tyson defines as the "colonized persons who did not resist colonial subjugation because they were taught to believe in British superiority and, therefore, in their own inferiority" (Tyson 2006: 421). In the same line of argument, Homi Bhabha highlights how in the discourse of colonialism, the objective is "to construe the colonised as a population of degenerate types on the basis of racial origin, in order to justify conquest and to establish systems of administration and instruction. (...) Colonial discourse produces the colonised as a social reality which is at 
once an 'other' yet entirely knowable and visible" (1994:70). It is thus these subjects, Baby Kochamma and Chacko, who are enforcing these behaviors on the twins and making the situation all the more confusing and frustrating for the children attempting to navigate their cultural divide. It is all the children can do to retreat from the awkward cultural collision and attempt a construction of the situation through the language they know. In this vein, the language they use to construct their situation is neither separate from the situation, nor fully explicative of it. It demonstrates Roy's ability to make amorphous the distinction between language and context, to demonstrate how language and context construct one another. In other words, how the twins reconstruct the reality of the situation through their internal linguistic lens.

As the novel goes by, many of Roy's techniques are indeed used for multiple purposes, and the different types of departures from standard English sometimes appear in close proximity. One of the most common types is the nonstandard use of capital letters. For example, Roy writes that Rahel "walked to the window and opened it. For a Breath of Fresh Air" (Roy 1998: 29). The appearance of capitals in phrases like this one causes the phrase to stand out, much like a proper noun. It highlights a phrase that native speakers take for granted. In many situations, this points out the stilted or unnecessarily formal phrases employed by some characters. In the previous example, the Breath of Fresh Air is taken as an established concept. It's a thing that everyone knows one can get at a window, not an original idea of the character that is born of her needs at the moment. In another example, Roy writes that "the air smelled of Something Burning" (Roy 1998: 11). Here, one can imagine Baby Kochamma sniffing the air and asking if anyone else smells Something Burning. The phrase is employed because it is common and established, even though in context it is clear what caused the smell (the dead bugs that destroyed themselves on Baby Kochamma's lightbulbs).

This highlighting of phrases that English speakers take for granted also serves to put this established, familiar English at a distance. In most cases, the capitals appear during the children's narration. This separates the children from the familiar but sometimes silly or arbitrary language of the English-speaking adults around them. The twins recall that "Miss Mitten... said that she was a Little Disappointed in them" (Roy 1998: 58). The phrase "Little Disappointed" is an established phrase of the English-speaking authority figure or disciplinarian. When capitals and other such mannerisms are then used during the narration of the adult twins, they form a connection to their younger selves and simultaneously show that the English language is still not yet wholly their own.

The use of sentence fragments is equally nonstandard and equally common. They are used partially as an aesthetic choice. Fragments introduce pauses, causing the text to flow in a rhythm more like natural speech or free thought than like typical prose. The typical mind does not think in long, flowery sentences but in a series of chaotically connected ideas. Structuring the narration of the characters with fragments is a far cry from a stream-ofconsciousness style of writing, but it makes the text seem more like a memory or reflection than an impersonal recounting of history.

In most uses, the fragments are used for apposition; that is, for substitution. Sometimes, for clarification, when used correctly; even for enlightenment, if used creatively. This style of constantly replacing, updating, and modifying phrases is not well-suited to a linear delivery 
of plot. It is, however, an excellent means of showing relationships between ideas. This decentralized style of setting up a complex web of concepts and events rather than directly telling a story may be considered a trademark of Roy's style in The God of Small Things, especially since it is even more clearly employed in the overall plot structure.

This use of fragments is exceedingly common. Some examples:

- "He began to look wiser than he really was. Like a fisherman in a city. With seasecrets in him." (Roy 1998: 14)

- "He held her as though she was a gift. Given to him in love. Something still and small. Unbearably precious." (Roy 1998: 20)

- "Rahel gave up her job at the gas station and left America gladly. To return to Ayemenem. To Estha in the rain." (Roy 1998: 21)

- "She occasionally wrote to Chacko and Mammachi, but never returned to Ayemenem. Not when Mammachi died. Not when Chacko emigrated to Canada." (Roy 1998: 19)

- "That it really began in the days when the Love Laws were made. The laws that lay down who should be loved, and how. And how much." (Roy 1998: 33)

- "[Sophie] had a special child-sized coffin. Satin lined. Brass handle shined." (Roy 1998: 6)

This style is certainly employed partially for simple aesthetic beauty and rhythmic flow, but it also allows the reader into the mind of the character at hand. The reader is not only placed in the character's perspective, but also the character's mind. The fragments seem almost like new ideas that are just occurring to the character as they think. As Cynthia Driesen comment, Rahel and Estha will also sometimes dissect a word "just to savor the enjoyment of the process of its disintegration" (1999: 368). They hear the word nictitating and find amusement in pulling it apart:

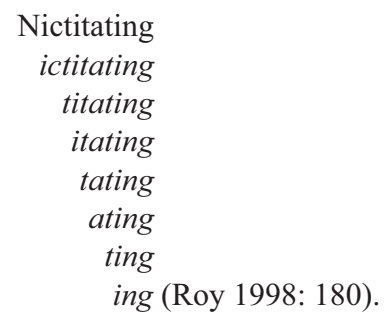

Here, Rahel's childhood play with words gives the reader a glimpse through the child's eye. This scene occurs while they are attending the funeral of their cousin, Sophie Mol, and instead of being serious and reverent Rahel is playing with words in her head, and gazing around the room, looking at the ceiling. This demonstrates the character of the twins and their buoyancy within a world of tragedy. "The clarity of the child's eye contrasts with and subverts the blinkered insensitivity of the adult world" (Driesen 1999: 369). 
This inside-the-head literary perspective also affords the reader glimpses into how the characters perceive language. In many cases, especially when focused on the young twins, this involves a focus on the sound of the words rather than the meaning. Roy plays with pronunciation, rhyming, and similarities of sound. In a different moment, Rahel is shown to be dreading her "Afternoon Gnap". This misspelling illustrates the disconnection between word and sound in the child's mind (and includes nonstandard capitalization for good measure). On another occasion, the twins "had to form the words properly, and be particularly careful about their pronunciation. Prer NUN sea ayshun" (Roy 1998: 36). Again, the focus is put on the sound, rather than the words. And again: "Chacko told Rahel and Estha that Ammu had no Locusts Stand I." This is, ironically, the twins' attempt to render in English a phrase of Latin legal jargon, locus standi. There are also instances in which the twins obviously do not understand the precise intended meaning of the sounds they hear, such as in Estha's singing of Elvis: "But moonin' an' a groonin' gonna satisfy mah soul, less have a pardy..." (Roy 1998: 37). This also occurs with more regular words: "It was an awe-inspiring and humbling thought, Chacko said (Humbling was a nice word, Rahel thought. Humbling along without a care in the world)..." (Roy 1998: 53)

Roy also plays with the construction of English words. After the twins discover the beauty of the addition of "cuff" and "link" into "cuff-link", new words are formed by similar addition. Examples include:

- "Baby Kochamma screamed and hit the air with her hymnbook. The singing stopped for a "Whatsit? Whathappened?" and for a Furrywhirring and a Sariflapping" (Roy 1998: 8)

- "She heard (on Sophie Mol's behalf) the softsounds of the red mud and the hardsounds of the orange laterite that spoiled the shining coffin polish. She heard the dullthudding through the polished coffin wood, through the satin coffin lining" (Roy 1998: 8-9).

- “And Estha, walking on the riverbank, couldn't feel the wetness of the rain, or the suddenshudder of the cold puppy that had temporarily adopted him and squelched at his side" (Roy 1998: 15).

- "A shrillwhistle blew" (Roy 1998: 77).

Like the capitalization, this serves to disconnect the character and the reader from the English language that native speakers take for granted. It makes us conscious of how the words actually sound, and, like the phenomenon of semantic satiation, that consciousness serves to sever words from their meaning. That is, a focus on the sound of words makes the reader feel as though he or she did understand English as a second language. It puts the reader at a distance and makes English feel foreign, less natural, and disconnected.

On many occasions, these techniques are combined or used in close proximity. For example, Roy uses rhyming and fragments together: "Not old. Not young. But a viable die-able age" (Roy 1998: 5). Later, she employs sound play and capitals: "Her funeral killed her. Dus to dus to dus to dus to dus. On her tombstone it said A Sunbeam Lent To Us Too BRIEFLy. Ammu explained later that Too Briefly meant For Too Short a While" (Roy 1998: 9). All of Roy's techniques work towards the same end: to put the reader's own language at 
a distance. Use of fragments firmly places the reader in the mind of the relevant characters. Use of capitalization and playing with sound puts that mind at a distance from the language. Roy separates English from English-speakers

On a different level, the imposition of language on the twins then twists this distance into a postcolonial framework. Proper English is not a choice. The twins must always speak English. The twins must never read backwards. They have a perspective that seems to treat English as difficult or curious, but any resistance is slowly being beaten out of them.

Even more striking, as already seen, the imposition of English comes at the hands of Indians. Chacko bemoans the mental colonization of India and labels the family as Anglophiles, but he does so while driving them all to see The Sound of Music. To explain what he means, he turns to the authority of the Oxford English Dictionary. The whole family treats English with great respect, almost reverence, almost as a measurement of personal worth. This symbolizes how Chacko and Baby Kochama are fully aware of their colonization, but choose not to fight it. As Ene-Reet Soovik points out "Roy's novel adopts the perspective that projects the English as the most visible and most desired cultural and racial other for these characters. At the same time, the futility of the self-destructive core of the attempt to become as English as possible is acknowledged as well" (2008: 171). Baby Kochamma's eagerness, for instance, to impress Margaret Kochamma at the airport by quoting Shakespeare implies an excessive lust for all things Western. She asks a pre-teen Sophie Mol “"D'you know who Ariel was?...Ariel in The Tempest?'” (Roy 1998: 138), as if this Shakespearean play were a foundational text for all young English children. The irony is Baby Kochamma's display (and it is merely a display, as Estha and Rahel can both see she is boasting) fails to see the colonial narrative between the play's Caliban and Prospero. Roy plants a western allusion embedded with colonial ideology in her character's dialogue with the representative of the colonizer, Margaret Kochamma. Roy's play on language here uses the western convention of allusion to illuminate the contradictory and ignorantly self-degrading project of a colonial subject; and thus, Baby Kochamma fails to see her own destructive fumbling.

Likewise, Baby Kochamma's constant insistence on speaking English, her obsession with Western television and products, and her grudge from never marrying the Roman Catholic Father Mulligan serves to prove Chacko right about his being a family of Anglophiles. The fact that "He made Rahel and Estha look up Anglophile in the Reader's Digest Great Encyclopaedic Dictionary" demonstrates one important dilemma of being Anglophiles: they can only understand themselves as such in the English language. They were "trapped outside their own history and unable to retrace their steps because their footprints had been swept away," (Roy 1998: 51) and because their means to understanding language was through an English dictionary. The only way they understood their alienation from their origins was through the constructions of the foreign, through their English. They do not have the cultural tools to understand their estrangement through Malayalam. In developing characters that are obsessed with all things English, with speaking only in their second language, and in viewing the world in terms of Western culture (i.e. Baby Kochamma's reference to The Tempest), Roy has set up a cast who are trapped both "outside their history" and within their text, a predominantly English prose of double-conscious themes and complex identities. 
As they gradually lose their original cultural roots, they lose part of their identity. They are hybrids now, and so it's their culture.

While Roy's use of language operates to assign confusion to the twins and draw readers into that same feeling, it also mimics and directs the colonial subject, but in addition to these two purposes it serves as a means of rebelling against those colonial constraints of language. Throughout the novel, we also see how Rahel and Estha often read signs or spell words backwards, as in Rahel's reading of a stop sign as "POTS," or Estha's reading "BE INDIAN, BUY INDIAN" as "NAIDNI YUB, NAIDNI EB" (Roy 1998: 57). These are acts of transgression that demonstrate the twins' rebellion against the English-izing of their culture, as the sign about being Indian is written in English. Such transgressions throughout the book represent a rejection of colonization and the attempt to escape the fate of the colonial subject. They enable Rahel and Estha to maintain some sense of agency over the language through which they construct and perceive the world. Whenever the twins read backwards it is of great irritation to Baby Kochamma, but in effect they are subverting her imposition of rules-rules established by the English-speaking British and internalized by her as an anglophile. They read backwards not only out of fun and entertainment, but out of spite for the way things ought to be, the way things are, as Baby Kochamma seems to think. Yet Roy employs other means of transgression to the English language. She consistently plays with language, as in capturing the sound of Rahel's giggle in the airport with a "Pffft!" (Roy 1998: 138). Her language here recreates the English language, molding it to transgress the traditional grammar taught in schools, while simultaneously commanding her writing with unmatched deliberateness and tact. Her new English creates something native English speakers have a difficult time grasping at first, both causing a sense of confusion for Western readers that the colonized felt, and unlocking a new expression of Indian identity. As much as her characters transgress the norms of the language, the novel itself does so as well, manipulating grammar, capitalization, spelling, and even structure, as past and present are constantly shuffled in the narrative structure. Moreover, this writing technique enables Roy to comment on the malleability of language. The twins' words are at once a rejection and a liberation. It is the same for Roy who constructs a reflection through these words on the very text she is writing. She is both confined by English and liberated by its malleability.

Finally, the language in Roy's novel reflects a reconciliation with English, a hybridization wherein Malayalam is incorporated into English text. It is not always a smooth hybridization and certainly comes with caveats, but it nonetheless seeks to create a new or modified language. As Elaine Stratford points out, "language is critical to how we view ourselves, each other, and the world; in a very real sense, language speaks us" (cited in Patel 2008: 230). Fluidly hybridizing English and Malayalam, Kuttappen, Velutha's brother, explains to the twins that "This river of ours... [pretends to be] a little old churchgoing ammooma, quiet and clean...idi appams for breakfast, kanji and meen for lunch. Minding her own business" (Roy 1998: 201). Roy retains the essence of the river through this language, thus emphasizing its importance in the mythos of their town. Employing Malayalam words to describe the river, Roy retains the characters' native language and thus their ability to name. Such an effort maintains their traditional language and their agency in integrating that language with English. It, in essence, creates a hybrid language, establishing some 
reclamation of the traditional language while ushering in a jagged form of the colonial, and modified, English.

In an interview with Reena Jana in 1997, Roy comments: "How can one define India? There is no one language, there is no one culture. There is no one religion, there is no one way of life. There is absolutely no way one could draw a line around it and say, 'This is India' or, 'This what it means to be Indian." Here, she argues against the tyranny of the idea of a single pure culture with a single language that is identifiably or authentically Indian. By contrast, she advocates the recognition of the inherent hybridity and plurality of the nation.

Roy's vast applications and reapplications of language at once rejuvenates, appropriates, and modifies an entire lexicon. English, the embodiment of colonialism and a means of colonizing, imposes its history upon any speaker. Throughout the novel, it is Rahel and Estha who resist this imposition, resist the acquisition of 'proper' English knowing it leads to the acquisition of an ideology. It is Roy's refashioning of language that leads to not only complex characters and narrative themes, but also real implications for the English language outside the text. It creates a post-colonial language that questions, subverts, and recasts the dominant language of today. Like Raja Jao who acknowledges, as we saw in the epigraph, the hybrid nature of Indian writers, Roy's Inglish in The God of Small Things represents a claim to bring to life the voice of those Indian citizens that grew up being subject to the influence of two or more languages, being English one of them. Although the latter was initially imposed on them, it eventually turned out to be the best way to reflect their hybrid conscience. Inglish became thus a language to assert themselves and vindicate their own identity. Today, Indian literature has a strong voice through which to express itself, a voice using the English language but with an injection of uniquely Indian forms, concepts and experiences.

\section{REFERENCES}

Bнавна, H. K. 1990. "DissemiNation: Time, Narrative, and the Margins of the Modern Nation.” In Bhabha, Homi K. (ed). Nation and Narration. London and New York: Routledge.

Внавна, H. K. 1994. The Location of Culture. London and New York: Routledge.

Driesen, C. V. 1999. "When Language Dances: The Subversive Poer of Roy's Text in The God of Small Things." Arundhati Roy: The Novelist Extraordinary. Ed. R. K. Dhawan. New Delhi: Prestige Books. 365-76.

JANA, R. 1997. Interview with Roy. http://www.salon.com/sept97/00roy2.html

Lane, R. J. 2006. The Postcolonial Novel. Cambridge: Polity Press.

Roy, A. 1998. The God of Small Things. New York: HarperCollins.

Patel, S. 2008. "The Difficulty of Being; Reading and Speaking in Arundhati Roy's The God of Small Things." Embracing the Other; Addressing Xenophobia in the New Literatures in English. 227-243. 
Snell-Hornby, M. 2003. "Re-creating the Hybryd Text: Postcolonial Indian Writings and the European Scene. Linguistic Antverpiensia, 2: 173-189.

SooviK, E. R. 2008. "Polyphony by a Polluted River in Arundhati Roy's The God of Small Things." Seeking the Self-Encountering the Other; Diasporic Narrative and the Ethics of Representation. 168-180.

Tyson, L. 2006. "Postcolonial Criticism" Critical Theory Today: A User Friendly Guide. New York: Routledge

Volkmann, L. 2008. "Arundhati Roy, The God of Small Things." Teaching Contemporary Literature and Culture. 463-479.

Young, R. J. C. 1995. Colonial Desire: Hybridity in Theory, Culture and Race. London and New York: Routledge. 